\title{
FRAMEWORK FOR A LEARNING MANAGEMENT SYSTEM AT A UNIVERSITY OF TECHNOLOGY WITH A WEAK INFORMATION TECHNOLOGY MATURITY SYSTEM
}

\section{P. Machika*}

Centre for Academic Development

e-mail: paulinema@vut.ac.za

\section{F. Dolley*}

e-mail: moegammatd@vut.ac.za

*Vaal University of Technology

Vanderbijpark

\section{ABSTRACT}

In the past, adoption of the learning management system (LMS) has been voluntary with a limited amount of training at the micro level within a particular university of technology. From discussions with academic staff it emerged that across the entire institution approximately 10-15 per cent of academic staff used a particular LMS with only about 5 per cent actively engaged. As the particular university progresses its broader plans for teaching and learning enhanced by technology, the LMS will become increasingly important as a tool to help realise the university's goals. The aim of the article is to gain a clear understanding of the potential barriers and obstacles encountered when implementing an LMS at a macro and meso level where the information technology system is weak. The article includes a discussion on a framework in support of the development of the LMS at a macro and meso level within a university of technology.

Keywords: weak information technology, learning management system, implementation, institutional, departmental and faculty levels, a framework to support the enhancement of the LMS, implementing an LMS at a macro and meso level, potential barriers and obstacles, an interpretive paradigm

\section{INTRODUCTION}

Research on learning management systems and the implementation thereof in South Africa has focused on cases studies at the micro level and hence not much is known of the implementation at the institutional, departmental and faculty levels, which are at the macro, meso and micro levels, and the connections between them.

Brown and Czerniewicz (2008) argue that there is limited research on how a learning management system (LMS) should be implemented at the macro or meso level within a 
university of technology (UoT) where the maturity of the information technology system is very weak. Further Linckels, Kreis, Reuter, Dording, Weber and Meinel (2009) highlight that within higher education in South Africa not much is known about information and communications technology (ICT). In particular, there is uncertainty regarding the effective implementation of an LMS, especially in relation to a university of technology at the macro, meso and micro levels.

An LMS can be defined as a "virtual and collaborative learning environment" designed to act as a focus for students' learning activities and delivery of educational courses using the internet as a delivery (http://www.e-learningconsulting.com/products/learning-managementsystem.html). Wang (2003) explains that an LMS is a special type of information system that focuses on teaching and learning, and Gremu and Halse (2012) notes that an LMS does not require students to be in the same location as their lecturers, which allows for flexible learning. In research conducted by Mtebe (2015) it was found that the use of the LMS has increased in higher education institutions in sub-Saharan Africa.

Certain factors improve the chances of success when implementing an LMS in a university-wide approach at a macro, meso and micro level; these include careful planning, the implementation of needs-based skills development for lecturers and students so as to ensure meaningful adoption of the technology, and tactics at a university-wide or a faculty, departmental or service level (Hannan and Silver 2000). At the UoT under review in this article, the above-mentioned factors for the successful university-wide implementation of an LMS are not visible as part of the e-learning strategy. Currently the UoT under discussion implements multiple LMSs which are not widely adopted by users at the macro, meso and micro levels. This shortcoming hinders the advancement of an initiative that will embed the LMS within the institution. Currently the successful implementation of an LMS rarely exists at the macro level at the UoT under study, making infrastructure and support issues real obstacles at the individual (micro) level. In the past, the adoption of the LMS was voluntary, with a limited amount of training at the individual level within the UoT. Given the challenges such as access, infrastructure and support, the result is a low adoption rate amongst users at the UoT at both the meso and the micro level.

This article is based on qualitative research that utilised an interpretive paradigm with content analysis as research design. The research process involved interviews with key users from the faculties and central services in addition to two days of planning which covered many strategic and tactical issues necessary to develop implementation of the LMS at the macro and meso levels. A survey was also conducted among 400 students concerning their digital footprint and identity within the institution under study. 
From discussions with academic staff it emerged that across the entire institution approximately 10-15 per cent of academic staff used a particular LMS with only about 5 per cent actively engaged. Additionally, numerous staff commented that if the infrastructure challenges could be removed many academics would engage with an LMS as they were enthusiastic about being part of a digitally enabled university within an engaged community.

The aim of the study was to gain a clear understanding of the implementation of an LMS by a UoT at macro, meso and micro level. A further aim was to develop a framework to support the enhancement of the LMS at a macro, meso and micro level. The study was based on a clear understanding of potential barriers and obstacles when implementing an LMS in a UoT where the information technology system has a low level of maturity.

As the particular UoT progresses its broader plans for teaching and learning enhanced by technology, the LMS will become increasingly important as a tool to help realise the university's goals.

\section{LITERATURE REVIEW}

Hannan and Silver (2000) provide an outline for what will differentiate learning and teaching in the future, and argues that it is not the content that will determine the success of such an initiative, but the ability and skills of academic staff to engage with students and encourage learning through a mix of traditional and learning management tools, at the micro, macro and meso levels. Within this context, the issue for a UoT is not whether value can be added but how to advance an initiative that will embed the LMS within the organisation and maximise the benefits at a micro, meso and macro level towards academic success.

The effective management and operation of an LMS within a university involves many stakeholders and usually requires the resolution of numerous cross-institutional issues, which must be coordinated and driven forward (Brown and Czerniewicz 2010) at the macro, meso and micro levels of the institution. According to Unwin (2007), such action should take place between a senior sponsor of the innovation and institutional stakeholders to ensure that the potential barriers, obstacles and issues of the institution are taken into consideration during the implementation. Without clear responsibility for these matters such possible challenges are frequently left unaddressed, significantly reducing opportunities for the LMS to be adopted by all stakeholders.

The primary obstacle to progress occurs if all of the key stakeholders at a micro level who have a responsibility for the implementation of an LMS work within a coordinated common vision and set of goals, with clear ownership and management responsibility for delivery. If this 
goal can be achieved - where all the players have a clear understanding of what needs to be done, in particular what their role should be and how important it is for all stakeholders to work together - then the UoT has the potential to move forward strongly at both the macro and meso level (Spencer 2011). Butcher (2015) points out that such an approach can be supported by ensuring that stakeholder input will focus on and include the following areas:

- $\quad$ enhancing the effectiveness and efficiency of the UoT's teaching and learning approaches;

- $\quad$ increasing student engagement with technology; creating extra learning opportunities for students;

- $\quad$ increasing access to the learning management system for students;

- $\quad$ improving student success;

- $\quad$ introducing greater peer support options for students;

- $\quad$ providing students and academics with additional resources;

- $\quad$ increasing student responsibility for engagement with the learning management system;

- $\quad$ reducing staff workload (academic and administrative) and streamlining business processes;

Universities in sub-Saharan Africa have shown wide and an ever expanding adoption of the LMS. Heeks (2002) contends that many information systems implemented in developing countries are doomed to partial or total failure. The implementation fails because it is not linked to improving the quality of teaching and learning through the development of a teaching and learning model. Other challenges are widening access to education and reducing the cost of delivery. Research trends emerging from developing countries show that once users are trained they do not utilise the system. According to Dube and Scott (2014), of the 10000 users that were trained to use the LMS at the National University of Science and Technology of Zimbabwe, only 20 per cent utilised the system. The same trend, namely increased adoption of the LMS but low usage thereof, was also reported in Zimbabwe by Chitanana, Makaza and Madzima (2008), as well as in other countries such as, Mozambique (Unwin et al. 2010), Uganda (Mayoka and Kyeyune 2012), and Sudan (Elmahadi and Osman 2013).

A major reason for the low adoption of the system can be related to the lack of feasibility studies being conducted before the implementation of an LMS to ensure that the appropriate LMS meet the needs of the institution. Ssekakubo, Suleman and Marsden (2012) argue that it is therefore not clear whether existing LMSs can be used by students in African universities because feasibility studies have not been conducted. For instance, at Makerere University in 
Uganda, 84.4 per cent of students and 79 per cent of faculty members indicated that the LMS was not easy to use (Mayoka and Kyeyune 2012). These authors' research findings highlight the need for feasibility studies to be conducted prior to the implementation of a system so as to link the implementation to the needs of the users. Mtebe (2015) argues that many usability problems can be fixed through conducting a feasibility study before implementation of the LMS, thus increasing the usage of the LMS, as the system will be easy to learn, easy to use and user friendly.

Furthermore, low adoption by the users of the system can also be linked to the existence of a lack of support services, as found in a study by Unwin et al. (2010) among 358 respondents from 25 African countries. These researchers found that 75 per cent of respondents indicated a lack of training and appropriate technical support as a reason for low adoption of the LMS. Similar studies, such as the investigation by Bhalalusesa, Lukwaro and Clemence (2013) at the University of Tanzania, have also indicated a lack of support services as the main reason for low adoption. In another study at four universities in Zimbabwe, 76 per cent of the respondents also cited this as the reason for low adoption by users of the LMS. In research conducted with 503 respondents, Tella (2012) found that a lack of support services at the University of Botswana was the main reason behind the low usage of the LMS. In the light of this finding Mtebe (2015) contends that in order to maximise LMS usage, institutions should establish functional information technology units to provide support services to both students and staff. Furthermore, according to Mtebe (2015), these units should be equipped with qualified staff with both technical and pedagogical skills to be able to provide appropriate support.

The LMS has the potential to add significant value to these institutions if it is implemented in a well-structured and targeted way at the macro and meso level. This significant value was seen in a study by Jo, Kim and Yoon (2014) at the Ewha Women's University where regular usage of the LMS is a strong indicator for improving student performance for courses offered online. The strategic deployment of an LMS facilitates developments and benefits which should include a major review and streamlining of the processes to ensure effective deployment in terms of the maturity level of the institution's information technology system. Such an approach can add considerable value to an institution in terms of its operational efficiency and the quality of service it provides to all stakeholders (Roca and Gagné 2008) at the macro, meso and micro levels.

A unified LMS environment could help strengthen the UoT community and identity, and establish greater consistency across the university and its various campuses (Sun, Chen, Finger, Tsai and Yeh 2008). It would allow the university to expand its presence through a virtual 
infrastructure without increasing the physical state while acting as a vehicle for pedagogic and broader change (McLeod, Pippen and Mason 2009). Mtebe (2015) states that the abovementioned aims can only be achieved if the environment makes it possible for all staff to make use of the technology.

\section{RESEARCH METHODOLOGY}

The study was based on qualitative research utilising an interpretive paradigm with content analysis as research design. A document analysis of an LMS was conducted to identify the aims and the nature of the changes required. Group interviews were conducted with lecturers to establish the nature of the current teaching, learning and assessment of discipline-specific practices. The process involved interviews with key stakeholders from the faculties and central services in addition to two days of planning which covered many strategic and tactical issues necessary to develop the LMS.

\section{PARTICIPANTS}

Ninety lecturers participated in the group interviews and were identified as attendants of the inhouse staff development conference at the UoT during the first semester of 2014. Interviews were scheduled to take place during the last week of October 2014. Nine group interviews were conducted. The group interviews involved 10 academic staff members per group. Staff members were from the following disciplines: Accounting, Bio-Science, Chemistry, Communication, Education, Engineering, Information Technology, Legal Science, Management Science, and Sport Management, and three participants were from various support services. The interview guide contained the following questions:

1. What are the users' expectations of a learning management system?

2. What limitations do users experience using a learning management system?

- What barriers do they experience?

- What are the potential barriers and obstacles they encounter with the current learning management system?

Participation was voluntary and the participants' anonymity was assured. All information would remain confidential. 


\section{DATA ANALYSIS}

The qualitative data analysis of transcriptions of the in-depth interviews was done with the use of ATLAS.ti software. Qualitative content analysis, following the steps suggested by Henning, Van Rensburg and Smit (2004), was the method of analysis. These steps imply an inductive approach involving fine coding, categorisation of codes and identification of themes.

\section{RESULTS}

\section{Macro level}

A potential barrier and obstacle identified by the respondents is the unreliability of the system at a macro level. If the system is not stable it does not only add to the lecturer's workload but also affects the motivation levels of the lecturer, as indicated by one of the interviewees: "I started asking [information technology staff] for help and they also tried but nothing worked and I was left with no choice but to cancel the test”. Other lecturers also mentioned problems with using the LMS for assessment, for example: “The moment there is a load on the system ... the server can't cope”.

As a result of potential barriers and obstacles, institutional innovations such as the LMS are often implemented at a micro level by individuals and not at a departmental or faculty level or at a university-wide level (Brown and Czerniewicz 2008). These factors can influence the sustainability of the LMS considerably. The UoT under discussion implements a multiple LMS; this creates further constraints as illustrated by the following remark: "I've heard of this Sakai but I don't want to get involved because it is more work for me”.

The successful implementation of the LMS is affected by the potential barriers within the institutional system. The situation is exacerbated when there is a severe shortage of hardware and the system is not stable, as indicated by the following remarks by a participant: "We have approximately 90 (P 301) and 100 (Gym Hall) computers available for 18 000+ students on campus”. As a result of the potential barriers in the system, lecturers develop a negative attitude towards the LMS. This is reflected in the following excerpt: "We loaded our learning guides on Sakai, but when I try to access the information under my name and password I can't see my learning guide". Another respondent stated that "nothing works - at the moment I am using my LMS as a glorified file server”. This last remark also indicates a barrier experienced by staff who do not have regular access to the LMS; it becomes a repository of information, as argued by Morrow (2007). Another respondent of the system reflected: "There is no one in our faculty we are employing currently for e-learning ... I am just uploading announcements to the students 
now and again and also I upload their study guide”.

\section{Meso level}

Lecturers face the challenge of having to undergo training to use the LMS effectively, as is illustrated by the following remark: "We never expose our lecturers to a blended approach, so how do we expect our students to adapt to a blended approach of learning?” One participant responded as follows: “... how else can we use the learning management system? We have not been trained. We have not been trained on how we get to upload our tests or ... We do not know how effective that tool can be. We are not using it as it should be, yet the UoT invested in it. So that is training, we need as well on using the e-learning management system effectively. How else can we use the learning management system?’ These responses are aligned with Selwyn's (2010) call for a move beyond technicality, to include pedagogy. Selwyn emphasises the need to understand the social and political structures within which the LMS functions in order to be aware of the possible influence of potential barriers and obstacles and issues on the system's functioning.

\section{DISCUSSION}

\section{Implementation at the macro level}

The research results of potential barriers and obstacles showed that certain strategic decisions should be taken by the university. It was important for the university to implement an LMS that could be reliable, accessible and work well in order to ensure that lecturers would not become frustrated when loading assessments and using the system. Thus, in 2013, the council of the UoT took a strategic decision to buy a proprietary-based system that would be externally hosted by the provider. The council recognised that it did not have the necessary maturity in its information technology system to support an open source system. Sun et al. (2008) argue that a unified LMS environment could help strengthen the UoT community and identity, and establish greater consistency across the university and its various campuses. Bringing about effective learning, however, is a complex and creative process which involves identifying objectives, recognising the needs of the user, selecting the most suitable approach, and then striking an appropriate balance between the LMS and other modes of delivery when working within a technology-rich context; one in which practitioners can choose between the LMS and traditional options (JISC 2004).

Through this strategic decision the university sought to ensure that the system would be 
fully operational and functioning with all its LMS functionalities and that all its users would subsequently adopt the system. This decision does not limit the opportunity to implement an open source system at a later stage when the information technology system within the UoT is more mature. As reflected in the research results, it is essential that the system at the macro and meso level is reliable and accessible, as often, when it is not, lecturers suffer and feel that the LMS is increasing their burden rather than lightening it. For this reason the university made use of a feasibility study with an outside consultant to understand how best to implement the LMS. This approach is supported by the work of Mtebe (2015) who argues that through conducting a feasibility study before the implementation of the LMS many usability problems can be fixed. The feasibility study can determine what kind of LMS would be implemented by the institution. If a feasibility study is not conducted the consequences can be dire, as emphasised by Ssekakubo et al. (2012). These authors point out that it was not clear whether LMSs could be used by students in African universities, because feasibility studies had not been conducted. In a study by Mayoka and Kyeyune (2012) at Makerere University in Uganda, where no feasibility studies had been conducted, 84.4 per cent of students and 79 per cent of faculty members indicated that the LMS was not easy to use.

In a study conducted by Unwin et al. (2010), based on a survey of 358 respondents from 25 African countries, 75 per cent of the respondents indicated a lack of training and appropriate technical support as a reason for low adoption of an LMS. Similar studies, such as the investigation by Bhalalusesa et al. (2013) at the University of Tanzania, have also indicated a lack of training and technical support as the main reasons for low adoption. In another study at four universities in Zimbabwe, 76 per cent of the respondents also cited these as reasons for the low application of the LMS. In research conducted among 503 respondents, Tella (2012) found that a lack of support services at the University of Botswana was the main reason behind the low usage of the LMS. In the light of this finding Mtebe (2015) states that in order to maximise LMS usage institutions should establish functional information technology units to provide support services to both students and staff.

The LMS has the potential to add significant value if implemented in a well-structured and targeted way at both the macro and the meso level. This significant value was seen in a study by Jo et al. (2014) at the Ewha Women's University where regular usage of the LMS is a strong indicator for improving student performance for courses offered online. A champion was identified at the UoT with the appointment of the Deputy Vice-Chancellor (Academic and Research) in October 2014, who could drive the implementation at a strategic level. This development is aligned with the research findings of Unwin (2007), who states that the role of 
a senior sponsor should not be underestimated.

It is important that the deployment of the LMS be implemented and aligned with the theory and practice of the teaching and learning model of the institution, since lecturers often view the LMS as a repository system for course material.

The research results indicated that often when the LMS does not work correctly it becomes a glorified file server. So it is important that the deployment of a LMS goes hand in hand with the development of a teaching and learning model, a policy framework and an implemental strategy.

As a result, the UoT under study has initiated the design and development of a new teaching and learning model aligned with the implementation of an LMS and in particular blended learning as a strategic initiative. The aim was to have completed the design and development of the teaching and learning model by June 2016. The focus would be on the policy landscape in support of teaching and learning and would address various pertinent focus areas through consultation with stakeholder input championed by the office of the Deputy ViceChancellor (Academic and Research). These pertinent focus areas are enhancing effectiveness and efficiency of the UoT's teaching and learning approaches; increasing student engagement with technology; creating extra learning opportunities for students; increasing access to the learning management systems for students; improving student success; introducing greater peer support options for students; providing students and academics with additional resources; harnessing the potential of open educational resources; increasing student responsibility for learning; reducing staff workload (academic and administrative) and streamlining business processes; developing students' practical skills through use of technology, thereby developing work-ready graduates; building staff technical literacy; monitoring at-risk students and intervening proactively where needed to improve throughput and success rates; and ensuring that e-learning is reliable and accessible (Butcher 2015).

The research results highlight at the macro level a need to address the policy gap which encapsulates how the LMS will be implemented. The UoT policy and strategy document will be developed through a consultative process based on the needs of the institution, faculties, departments and individual academics. With regard to the policy and strategy document it is important that faculties and departments commit to an institution-wide blended mode as a development policy and process that will enable the UoT to embed and secure the benefits of the LMS. This view is supported by the work of Butcher (2011) who states that the policy will provide guidelines regarding access to and use of the institution's appropriate ICT infrastructure and educational resources. 
At the macro level the LMS was integrated with the information technology system of the university in 2015, so that every academic module registered on the Higher Education Qualifications Framework by the UoT could be adopted onto the proprietary-based system and will be registered immediately when the user accesses it. A unified LMS environment could help strengthen the UoT community and identity, and establish greater consistency across the university and its various campuses (Sun et al. 2008). Current developments include the implementation of the grade book so that marks can be captured on the LMS and then integrated into the ITS.

Linked to the policy gap is the development of appropriate learning spaces which are connected to Wi-Fi where students can have access to the LMS. The research results outline the need for more computer labs and access to Wi-Fi across the institution especially in lecture halls. It should be noted that because of the weak maturity level of the information technology of the institution, the provision of Wi-Fi has become more critical to the implementation of the LMS at a macro level. It allows the university to expand its presence through a virtual infrastructure without increasing the physical state of the institution through the development of infrastructure. This enables the UoT to act as a vehicle for pedagogic and broader change (McLeod et al. 2009). It is through Wi-Fi that students can have access to the reliable proprietary-based system with their own devices that they bring to the institution, especially when the institution is unable to provide consistent ongoing technological support in its computer labs.

The research results show that, because of the limited implementation of multiple LMSs at the macro and meso level, the stakeholders at the UoT did not view the LMS as part of the integrated system of the university. To address the UoT's aim of achieving its strategic goals, there is a need for a structured change management initiative that provides leadership, decisionmaking, direction and a road map that will take the UoT from where it is today to where it wishes to be over the next five years or towards 2030. It is with this goal in mind that the drivers of the implementation of the LMS introduced change management workshops for all levels in the institution to be presented in late 2015 and early 2016.

\section{Meso level}

A new educational technology unit, which reports to the Deputy Vice-Chancellor (Academic and Research) through the Centre for Academic Development was established in the institution to drive the implementation and development of the LMS. This approach is supported by Mtebe’s (2015) recommendation that in order to maximise LMS usage, institutions should 
establish functional information technology units to provide support services to both students and staff and that these units should be equipped with qualified staff with technical and pedagogical skills to be able to provide appropriate support. In the light of Mtebe's comments, the UoTs focus is on employing staff who can enhance the pedagogical skills of the institution and provide functional information technology support to its academic users so as to enable them to adopt the technology to ensure academic success and throughput.

At a practical level the UoT will need to ensure that appropriate skills are available to advance activities by deploying in-house staff, recruiting new blood (instructional design and administrator skills), and drawing on external specialists to help fast-track activities and support the development process as appropriate.

Brown and Czerniewicz (2008) argue that if the adoption of the LMS does not occur at an institutional (macro) and faculty (meso) level, the implementation of a proprietary-based system will always remain slight and will not be institutionally driven. Brown and Czerniewicz (2008, 2010) emphasise that two important factors should be addressed at the meso level if an LMS is to be successfully implemented. The first is the need to tie the adoption of academic modules to performance management on a yearly basis. Such a move can ensure that academic staff members are kept accountable for the uptake of their modules. Performance management will also highlight any developmental needs that are required in terms of the LMS that can be fed back to the educational technology unit. This measure will ensure that the faculties determine how many modules should be adopted on the proprietary-based system per year. Each faculty is required to develop its own LMS operational plan outlining how e-learning and in particular how a strategy for blended learning should be implemented. These plans would include the LMS and the number of modules to be adopted yearly. Mtebe (2015) contends that the above-mentioned development can only take place if the environment enables faculty members to make use of the technology. This would be done in partnership and collaboration with the educational technology unit.

The second factor that is central to the implementation of the LMS is the training of academics. The research has shown that the implementation of the LMS will fail if the academics do not have proper, needs-based training. Furthermore, if the lecturers have not received the necessary support in the form of proper training, the students whom they teach will not feel comfortable with the adoption of the system.

Training at a faculty (meso) level is a complex matter as it can never be taken for granted that faculty members have understood how to utilise the LMS. Thus, training needs are ever evolving and need to be adjusted in terms of who requires particular training. This view is 
supported by Unwin et al.’s (2010) study involving 358 respondents from 25 African countries in which 75 per cent of the respondents indicated a lack of training and appropriate technical support as reasons for low adoption of the LMS. It is therefore evident that the different needs of academics should be clearly identified and utilised to customise training. It is important that the model of training be matched with the different needs of the academics within different departments, and that it may vary from department to department. Academics in some departments might still require old methods like using a manual while other departments may feel confident and would rather experiment with the system to achieve mastery during the posttraining period. It is with this approach in mind that two programmes of training are being implemented in departments at the UoT in question. The finding of Dube and Scott (2014), at the National University of Science and Technology of Zimbabwe, where only 20 per cent of the 10000 users that were trained use the LMS indicates that a dynamic training approach should be implemented. Thus, a first programme of generic training is offered as an introduction to the LMS and then a second programme is offered as follow-up training aimed at instructional design. After the users have been trained in the use of the tool by allowing them only to use one or two tools of an LMS, the second training programme enables them to engage in instructional design with their own modules to ensure uptake of the system. Being exposed to many tools of the system can be overwhelming for lecturers and often lead to a lack of adoption. This training programme is presented by the educational technology unit but it is also offered online and by outside providers in a two-day workshop. Academic staff are then supported by instructional and graphic designers to ensure that their modules are visually pleasing to students online.

The first generic training is conducted departmentally where users who teach a similar module can engage with ideas around innovation. The training is also conducted generically where users from different departments can engage with others in discussion. Research results show that fundamentally the training should be conducted for individuals who are fearful of using the system and need to be taken by the hand. It is important that such staff receive followup training on a one-on-one basis with a trainer they trust. Therefore, champion trainers who are trained as certified trainers are deployed in the faculty. Students also require training in the use of the LMS and this is done in two ways: through video technology and optimistic, confident trainers who are students and have a high profile on campus through the student representative council or student structures. These are students who have a big following of students on campus and have access to students within the faculty structure. Thus, they are able to utilise face-to-face training and video technology. Video technology demonstrates the use of the LMS in a step-by-step approach that is readily available to the student user either through smart phone technology or through the LMS, during lectures and on the student portal. 


\section{Framework for a learning management system at a university of technology with a weak information technology maturity system}

The research results and discussion highlight a framework emerging for the successful implementation of an LMS within a UoT where the information technology system has a weakened maturity level at both the macro and the meso level. Tables 1 and 2 present the framework as discussed in the discussion:

Table 1: Macro level of the UoT implementation

\section{Feasibility study}

- Determine the needs of the users as well as institutional needs.

- Determine the policy framework.

- Determine the staffing required for the implementation at macro and meso levels.

- Identify types of LMSs that are best suited for the UoT aligned with the need of the users and the UoT.

- Identify obstacles and challenges faced by the institution and determine how they can be addressed through the implementation, especially in relation to the weak information technology system.

Sources: Butcher (2011); Unwin (2007)

\section{Policy}

- Provides guidelines regarding access and the use of appropriate infrastructure.

- Developmental needs of staff can be identified and feedback given to the unit for educational technology.

Sources: Brown and Czerniewicz (2008; 2010)

\section{Impact of information technology system}

- Proprietary-based system for accessibility and access

- Integration of the LMS with the information technology system of the university

- Roll-out of the Wi-Fi

Source: McLeod et al. (2009)

\section{Champions}

- Identify champion or sponsor at a senior management level.

- Identify champion trainers at the faculty level. These are academics who are based in the faculty in addition to the trainers in the educational technology unit.

Source: Unwin et al. (2010)

\section{Change management process}

- Creation of a culture that is conducive to LMS implementation - explaining the need to implement and the benefits

- Ongoing information concerning the implementation of the LMS

- Roadshows for students and staff to ensure highly developed engagement with the LMS system

Source: Kasper (2008)

\section{E-learning unit}

- Qualified staff are employed with pedagogical and technical skills.

- Faculty operational plans outline the adoption of modules.

- Support is provided for users to access the system.

- Dynamic training programmes are offered.

Sources: Mtebe (2015); Brown and Czerniewicz (2008; 2010); Bhalalusesa et al. (2013); Tella (2012)

Table 2: Meso level of the UoT implementation

\begin{tabular}{|l|l|}
\hline Training & $\begin{array}{l}\text { Performance management } \\
-\quad \text { Individual academic staff adoption of modules }\end{array}$ \\
$-\quad$ Generic training & $\bullet \quad$ Identification of developmental needs of academic \\
- Instructional design training & staff in terms of the LMS and their pedagogical \\
$-\quad$ Follow-up support provided by instructional & Sources: Mtebe (2015); Brown and Czerniewicz \\
$\quad$ and graphic designers & $(2008 ; 2010)$ \\
- Champion trainers at the faculty level & \\
Source: Dube and Scott (2014) & \\
\hline
\end{tabular}

The framework pinpoints the fundamentals when implementing an LMS in a UoT where the information technology system is weak at both the macro and the meso level. From these 
fundamentals planners can develop the LMS and ensure it has been established for success and not failure.

\section{CONCLUSION}

By identifying the potential obstacles, barriers and issues encountered by users the study was able to pinpoint key strategic issues affecting the deployment of an LMS at the macro and meso levels at a university of technology. It was also possible to create an overall framework to support the development of the LMS where the information technology system has a low level of maturity.

The UoT's ambitions create many opportunities for the LMS to add significant value. The institution has made progress but needs to enhance this growth and focus on embedding the LMS within the organisational culture, which will take a sustained and well-managed effort. There is clear enthusiasm and recognition that with the right drive and support the LMS can contribute to the UoT's future success. This provides a solid base from which to establish a robust strategic framework and operational environment, which can be deployed to support future growth and development and contribute significantly to achieving the UoT's goals.

\section{ACKNOWLEDGEMENT}

Mr. Chris Steyn from the Vaal University of Technology is acknowledged for research inputs.

\section{REFERENCES}

Bhalalusesa, R., E. E. Lukwaro and M. Clemence. 2013. Challenges of using E-learning management systems faced by the academic staff in distance based institutions from developing countries: A case study of the Open University of Tanzania. Huria Journal of OUT 14: 89-110.

Brown, C. and L. Czerniewicz. 2008. Trends in student use of ICTs in higher education in South Africa. In Proceedings of 10th annual conference of WWW applications. Cape Town. 3-6 September.

Brown, C. and L. Czerniewicz. 2010. Debunking the "digital native”: Beyond digital apartheid, towards digital democracy. Journal of Computer Assisted Learning 26(5): 357-369.

Butcher, N. 2011. A basic guide to Open Educational Resources (OER). Vancouver \& Paris.

Butcher, N. 2015. Unpublished report on the teaching and learning model.

Chitanana, L., D. Makaza and K. Madzima. 2008. The current state of e-learning at universities in Zimbabwe: Opportunities and challenges. International Journal of Education and Development using ICT 4(2): 5-15.

Dube, S. and E. Scott. 2014. An empirical study on the use of the Sakai Learning Management System. In Proceedings of the e-skills for Knowledge Production and Innovation Conference, 101-107. Cape Town, South Africa.

Elmahadi, I. and I. Osman. 2013. A study of the Sudanese students' use of collaborative tools within Moodle Learning Management System. In IST-Africa 2013 Conference Proceedings, 1-8.

Gremu, C. D. and M. Halse. 2012. The educational value of integrating a social networking platform and a learning management system. http://www.cs.ru.ac.za/research/g12G1792/documents/ shortpaper.pdf 
Hannan, A. and H. Silver. 2000. Innovation in higher education: Teaching, learning and institutional cultures text. Philadelphia: Society for Research into Higher Education \& Open University Press.

Heeks, R. 2002. Information systems and developing countries: Failure, success, and local improvisations. The Information Society 18(2): 101-112.

Henning, E., W. van Rensburg and B. Smit. 2004. Finding your way in qualitative research. Pretoria: Van Schaik.

JISC. 2004. Effective practice with e-Learning. Higher Education Funding Council for England.

Jo, I., D. Kim and M. Yoon. 2014. Constructing proxy variable to analyze adult learnings' time management strategy in LMS using learning analytics. Paper presented at the conference of Learning Analytics and Knowledge, Indianapolis, IN.

Kasper, G. 2008. Intentional Innovation. In M. Institute (Ed.): Kellogg Foundation.

Linckels, S., Y. Kreis, R. Reuter, C. Dording, C. Weber and C. Meinel. 2009. Teaching with information and communication technologies: Preliminary results of a large-scale survey. Conference paper at the SIGUCCS Fall Conference, October 11-14, in St. Louis, Missouri, USA.

Mayoka, K. and R. Kyeyune. 2012. An analysis of e-learning information system adoption in Ugandan universities: Case of Makerere University Business School. Information Technology Research Journal 2(1): 1-7.

McLeod, A., S. Pippen and R. Mason. 2009. Individual taxpayer intention to use tax preparation software: Examining experience, trust, and perceived risk. Journal of Information Science and Technology 6: 25-44.

Morrow, W. E. 2007. Learning to teach in South Africa. Cape Town: HSRC Press.

Mtebe, J. S. 2015. Learning management system success: Increasing learning management system usage in higher education in sub-Saharan Africa. International Journal of Education and Development using Information and Communication Technology 11(2) : 51-64

Roca, J. C. and M. Gagné. 2008. Understanding e-learning continuance intention in the workplace: A self-determination theory perspective. Computers in Human Behavior (24): 1585-1604.

Selwyn, N. 2010. Looking beyond learning: Notes towards the critical study of educational technology. Journal of Computer Assisted Learning 26(1): 65-73.

Spencer, S. 2011. Universal design for learning: Assistance for teachers in today’s inclusive classrooms. Interdisciplinary Journal of Teaching and Learning 1(1): 10-22.

Ssekakubo, G., H. Suleman and G. Marsden. 2012. Learning management systems: Understanding the expectations of learnings in developing countries. In Proceedings of the IADIS International Conference, e-Learning 2012, 251-260. Lisbon, Portugal.

Sun, P. C., Y. Y. Chen, G. Finger, R. Tsai and D. Yeh. 2008. What drives a successful e-learning? An empirical investigation of the critical factors influencing learning satisfaction. Computers \& Education 50: 1183-1202.

Tella, A. 2012. System-related factors that predict students' satisfaction with the Blackboard Learning System at the University of Botswana. African Journal of Library, Archives and Information Science 22(1): 41.

Unwin, A. 2007. The professionalism of the higher education teacher: What's ICT got to do with it? Teaching in Higher Education 12(3): 295-308

Unwin, T., B. Kleesen, D. Hollow, J. B. Williams, L. M. Oloo, J. Awala, I. Mutimucuio, F. Eduardo and X. Muianga. 2010. Digital learning management systems in Africa: Myths and realities. Open Learning: The Journal of Open and Distance Learning 25(1): 5-23.

Wang, Y. S. 2003. Assessment of learning satisfaction with asynchronous electronic learning systems. Information \& Management 41(1): 75-86. 